\title{
Effect of Acid, Base and Time on Different Brands of Glimepiride
}

\author{
Safila Naveed*, Hina Qamar, Wardha Jawaid, Urooj Bokhari \\ Jinnah University for Women, Karachi, Pakistan \\ Email: safila117@yahoo.com, 'safila117@gmail.com
}

Received 2 June 2014; revised 4 July 2014; accepted 14 August 2014

Copyright (C) 2014 by authors and OALib.

This work is licensed under the Creative Commons Attribution International License (CC BY). http://creativecommons.org/licenses/by/4.0/

(C) (i) Open Access

\begin{abstract}
The objective of this study is to develop the degradation studies of different brands of glimepiride available in market. Forced degradation is a powerful tool used routinely in pharmaceutical development in order to develop stability-indicating methods that lead to quality stability data and to understand the degradation pathways of the drug substances and drugs. Glimepiride is a mediumto long-acting sulfonylurea antidiabetic drug as it is the most prescribed oral antihyper glycaemic agent indicated to treat type 2 diabetes mellitus. Its mode of action is to increase insulin production by the pancreas. This is not used for type 1 diabetes because in type 1 diabetes the pancreas is not able to produce insulin. Glimepiride was subjected to different stress conditions as per (ICH) International Conference on Harmonization guidelines. Distilled water was used as solvents and the amount of drug was calculated after degradation by taking absorbance at $200 \mathrm{~nm}$. According to the assay limit of USP specified that the content should not be less than $95 \%$ and not more than $105 \%$ of labelled amount. On basic $\mathrm{pH}$ brand $\mathrm{A}$, and $\mathrm{E}$ showed degradation after the addition of 0.1 $\mathrm{N}$ base while other brands degraded as base has no impact on glimepiride concentration. On addition of $0.1 \mathrm{~N} \mathrm{HCl}$ only brand E showed heavy degradation. After 48 hours the absorbance of all brands are different compared with initial absorbance which shows degradation of all brands.
\end{abstract}

\section{Keywords}

Glimepiride, Degradation Studies, Assay, USP

Subject Areas: Analytical Chemistry, Geometry, Medicinal Chemistry

\section{Introduction}

Forced degradation (FD) study is a process in which the natural degradation rate of a pharmaceutical product is increased by the application of an additional stress. FD studies 1) help to identify reactions that cause degrada-

*Corresponding author. 
tion of pharmaceutical product; 2) are part of the development strategy and an integral component of validating analytical methods that indicate stability and detect impurities which are formed during manufacture, their proper storage and their properties are different from the desired product with respect to activity, efficacy and safety; and 3) are designed to generate product-related variants and develop analytical methods to determine the degradation products formed during accelerated and long term stability studies [1] [2]. This article describes the mechanism of formation and characterization of generated impurities during force degradation studies in pharmaceuticals [3]. Force degradation studies ensure appropriate stability of final pharmaceutical products in very early stages of pharmaceutical development. Any significant degradation product should be evaluated for characterization and quantization for its potential hazard. While performing the forced degradation studies question may arise that how much amount for degradation is enough in stress testing. We classified the forced degradation into the following types.

1) Deceptive: Degradation level is good $(<15 \%)$ but no relevant degradants are observed.

2) Predictive: Degradation level is good $(<15 \%)$ but one or more relevant degradants are observed.

3) Useless: Between 15 to $100 \%$ degradation but no relevant degradants are observed [4].

Typical stress tests include four main degradation mechanisms: hydrolytic, heat, photolytic, and oxidative degradation. By selecting suitable reagents such as the concentration of acid, base, and varying the conditions (e.g., temperature), length of exposure can achieve the preferred level of degradation [3]. Over-stressing a sample may lead to the formation of secondary degradants that would not be seen in formal shelf-life stability studies and under-stressing may not serve the purpose of stress testing.

Glimepiride is an oral sulfonylurea. Glimepiride (Figure 1) is identified as 1-[[p-[2-(3-ethyl-4-methyl-2-oxo3-pyrroline-1carboxamido)ethyl] phenyl] sulfonyl]-3-(trans-4-methylcyclohexyl) urea (C24H34N4O5S) with a molecular weight of 490.62 [5]. Glimepiride is a white to yellowish-white, odorless to practically odorless powder and is practically insoluble in water. Glimepiride acts as an insulin secretagogue and it lowers blood sugar by stimulating the release of insulin by pancreatic beta cells and by inducing increased activity of intracellular insulin receptors.

As a result of the importance of this oral hypoglycaemic agent in the treatment of noninsulin-dependent diabetes mellitus DM, this work aims to compile the published analytical methods reported so far in the literature for determination of degraded products of glimepiride in biologic samples and pharmaceutical formulations [6]-[10]. Techniques like high-performance liquid chromatography with ultraviolet, mass spectroscopy, arraydiode, evaporative light scattering and liquid chromatography-atmospheric pressure chemical ionization-mass spectrometry, ionization-tandem mass spectrometry, high-performance liquid chromatography with columnswitching, micelle electro kinetic chromatography, high-performance thin layer chromatography, and spectrophotometry have been used for analysis, from which we have seen that high-performance liquid chromatography methods have been used most extensively [11] [12]. The aim of present work is to develop and validate a simple UV spectrophotometric method to be applied for analysis of glimepiride degradation in tablets, which serves as a tool for the quality control of pharmaceutical dosage forms. Spectrophotometry technique is generally preferred especially by small-scale industries as the cost of the equipment is less and the maintenance problems are cheap. UV spectrophotometric technique can be used for degradation studies of glimepiride. The active pharmaceutical ingredient is subjected to a number of forced degradation conditions to include acidic and basic conditions as per ICH guidelines.

\subsection{Parameters in Forced Degradation}

The forced degradation studies for drug substance include Temperature and or with humidity, Acid/base Stress testing, Time, Photo degradation and $\mathrm{pH}$ variation (high and low).

\subsection{Acid/Base Stress Testing}

Acid/Base stress testing is performed to force the degradation of a drug substance to its primary degradation<smiles>CCC1=C(C)CN(C(=O)NCCc2ccc(ONC(=O)NC3CCC([Tl])CC3)cc2)C1=O</smiles>

Figure 1. Glimepiride structure. 
products by exposure to acidic or basic conditions. The functional groups likely to introduce acid/base hydrolysis are compounds that have labile carbonyl functionality such as amides (lactam), esters (lactones), carbamates, imides, imines, alcohols and aryl amines [13].

\section{Experimental}

The glimepiride brands used were GLORY 4 mg; MEGAPRIDE 4 mg; GLIOPTIM 4 mg; DIABOLD 4 mg; GLYSET $4 \mathrm{mg}$ and AMARYL $4 \mathrm{mg}$ of sandoz, Mega pharmaceuticals, merck, barret hodgson Pakistan, Wilshire laboratories, sanofi Aventis respectively.

\subsection{Reagents}

The reagents were used all of analytical grade including hydrochloric acid, sodium hydroxide, Deionized water used was double distilled, deionized and filtered.

\subsection{Glassware's}

Volumetricflask, pipette, beakers, measuring cylinder, funnel, stirrer all the glassware's were of Pyrex type and were washed with chromic acid followed by thorough washing with water and finally rinsed with double distilled or de-ionized water which was freshly prepared in the laboratory.

\subsection{Equipments Used}

pH meter: Starter 2000 OHAUS, Spectrometer: T80 UV/VIS spectrometer PG Instrument ,Weighing Balance: Item PA214C ,Pioneer OHAIUS, Water Bath used is Digital constant temperature tank HH-4, the lamp which is used is Serial N 045571, LF-204.LS, 4W-254 nm, 4W-365 nm, Power: 8 N, used.

\subsection{Preparation of $0.1 \mathrm{M}$ Hydrochloric Acid}

$9.1 \mathrm{ml}$ hydrochloric acid of analytical grade $(36 \%, 11 \mathrm{~N}$ ) was taken in a liter volumetric flask and the volume was made up to the mark with de-ionized water.

\subsection{Preparation of $0.1 \mathrm{~N}$ Sodium Hydroxide}

$40 \mathrm{gm}$ sodium hydroxide was dissolve in very small quantity of water taken in a liter volumetric flask and the volume was made up to the mark with de-ionized water.

\subsection{Preparation of Glimepiride Solution}

Weigh and finally crushed tablets and weigh crushed tablets accurately for making primary solutions of Glimiperide, Megapride (0.1284 gm), Amaryl (0.170 gm), Glioptim (0.1381 gm), Diabold (0.1662 gm), Glory (0.1804 gm), Glyset (0.1837 gm) were weighed accurately and introduced in $100 \mathrm{ml}$ volumetric flasks. Then add $70 \mathrm{ml}$ of water and shake well for 15 min and makeup the volume, after that filter and discard first $20 \mathrm{ml}$ of filtrate. Dilute the solution $10 \mathrm{ml}$ to $100 \mathrm{ml}$ with water then again dilute $10 \mathrm{ml}$ of resulting solution to $100 \mathrm{ml}$ with water. Determine the absorbance at max of $200 \mathrm{~nm}$.

\subsection{Procedure for Degradation Studies}

\section{1) For time}

We placed the solution for 5 days and measure the absorbance after 2 days at the same wavelength $200 \mathrm{~nm}$.

\section{2) For acidic pH}

Place the final solution of glimepiride in a beaker and add $0.1 \mathrm{~N}$ hydrochloric acid HCL drop wise to the final solution and keep adding $0.1 \mathrm{~N}$ HCLuntil the $\mathrm{pH}$ reaches to 3 . Then determine the absorbance at $200 \mathrm{~nm}$.

\section{3) For basic pH}

Place the final solution of glimepiride in a beaker and add $0.1 \mathrm{~N}$ sodium hydroxide. Check the absorbance of this solution at maximum of $200 \mathrm{~nm}$. 
Table 1. Effect of acid base and time on glimepiride brands.

\begin{tabular}{ccccc}
\hline S.NO & BRANDS & \% ASSAY AFTER ACID & \% ASSAY AFTER BASE & \% ASSAY AFTER 48 HOURS \\
\hline A & GLORY & $91.6 \%$ & $117.43 \%$ & $97.96 \%$ \\
B & MEGAPRIDE & $95.83 \%$ & $92.03 \%$ & $99.3 \%$ \\
C & GLIOPTIM & $96.8 \%$ & $90.63 \%$ & $81.9 \%$ \\
D & DIABOLD & $96.7 \%$ & $91.03 \%$ & $80.3 \%$ \\
E & GLYSET & $174.22 \%$ & $179.83 \%$ & $154 \%$ \\
F & AMARYL & $94.04 \%$ & $88.52 \%$ & $78.9 \%$ \\
\hline
\end{tabular}

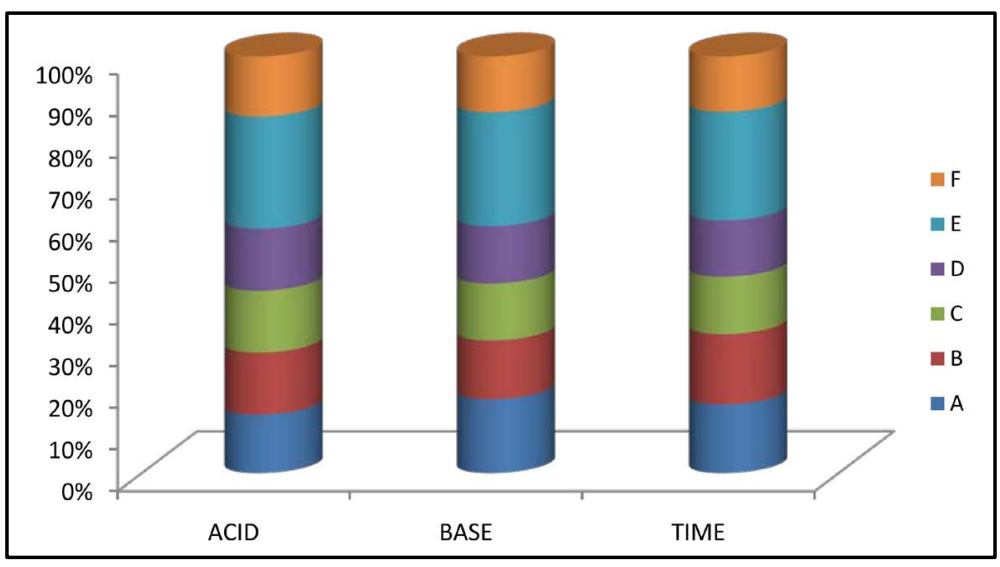

Figure 2. Effect of acid base and time on glimepiride.

\section{Results and Discussion}

\section{Degradation Studies}

The limit of assay by USP specified that the content should not be less than $95 \%$ and not more than $105 \%$ of labelled amount. All brands of glimepiride results were within the stated limit for assay before any degradation. Brand $\mathrm{E}$ degraded after the addition of 0.1 normal HCL into it showing acid has the least degradation impact on the product. Brand A and E showed degradation after the addition of $0.1 \mathrm{~N} \mathrm{NaOH}$ while other brands does not degraded as base has little impact on glimepiride concentration. Only brand $\mathrm{E}$ shows degradation after 2 days that was the effect of time on glimepiride (Table 1 and Figure 2). Our research group has performed these types of studies for different drugs and these are very helpful for pharmacy profession [14]-[16].

\section{Conclusion}

It was used to study the stress degradation studies as per ICH guidelines. Glimepiride was found to be degraded not in all types of stress conditions and was found to be stable. The proposed method is accurate and precise as well as reproducible and economical and can be successfully used degradation studies of different dosage form. It was concluded that only brand $\mathrm{E}$ showed unexpected results and most unstable among other brands for all the stresses applied for degradation studies, whereas only brand A showed degradation in stress of base.

\section{References}

[1] Singh, R. and Rehman, Z. (2012) Current Trends in Forced Degradation Study of Pharmaceutical Product Development. Journal of Pharmaceutical Education and Research, 3, 54-63.

[2] Zhou, L., Mao, B., Novak, T. and Ge, Z. (2007) Impurity Profile Tracking for Act Pharmaceutical Ingredients: Case Reports. Journal of Pharmaceutical and Biomedical Analysis, 44, 421-429.

http://dx.doi.org/10.1016/j.jpba.2006.11.004 
[3] ICH Q3B (R2) (2006) Impurities in New Drug Substances and Products (Step 4). International Conference on Harmonization, 86-95.

[4] Ahuja, S. (1998) Impurities Evaluation of Pharmaceuticals. Marcel Dekker, New York.

[5] Lakshmi, K.S., Rajesh, T., Sharma, S. and Lakshmi, S. (2009) Development and Validation of Liquid Chromatographic and UV Derivative Spectrophotometric Methods for the Determination of Metformin, Pioglitazone and Glimepiride in Pharmaceutical Formulations. Der Pharma Chemica, 1, 238-246.

[6] Lehr, K.H. and Damm, P. (1990) Simultaneous Determination of the Sulphonylurea Glimepiride and Its Metabolites in Human Serum and Urine by High-Performance Liquid Chromatography after Precolumn Derivatization. Journal of Chromatography B: Biomedical Sciences and Applications, 526, 407-505. http://dx.doi.org/10.1016/S0378-4347(00)82531-1

[7] Adithya, P., Vijayalakshmi, M., Rama Krishna, U.V. and Nihar Reddy, K. (2012) Stability Indicating Spectrophotometric Method for the Estimation of Glimepiride in Bulk and Various Marketed Brands of Tablets. Inventi Rapid: Pharm Analysis \& Quality Assurance, 4, 1-5.

[8] Khan, M.A., Sinha, S., Vartak, S., Bhartiya, A. and Kumar, S. (2005) LC Determination of Glimepiride and Its Related Impurities. Journal of Pharmaceutical and Biomedical Analysis, 39, 928-43. http://dx.doi.org/10.1016/j.jpba.2005.06.007

[9] Kovarikova, P., Klimes, J., Dohnal, J. and Tisovska, L. (2004) HPLC Study of Limepiride under Hydrolytic Stress Conditions. Journal of Pharmaceutical and Biomedical Analysis, 36, 205-209. http://dx.doi.org/10.1016/j.jpba.2004.05.005

[10] Sengupta, P., Bhaumik, U., Ghosh, A., Kanti Sarkar, A. and Chatterjee, B. (2009) LC-MS-MS Development and Validation for Simultaneous Quantitation of Metformin, Glimepiride, and Pioglitazone in Human Plasma and Its Application to a Bioequivalence Study. Chromatographia, 69, 1243-1250. http://dx.doi.org/10.1365/s10337-009-1056-5

[11] Prveenkumar Reddy, B, Boopathy D, Bibin Mathew, Prakash M, Perumal P, (2010) Method Development and Validation of Simultaneous Determination of Pioglitazone and Glimepiride in Pharmaceutical Dosage form by RP-HPLC. International Journal of ChemTech Research, 2, 50-53.

[12] Altinoz, S. and Tekeli, D. (2001) Analysis of Glimepiride by Using Derivative UV Spectrometric Method. Journal of Pharmaceutical and Biomedical Analysis, 24, 507-515. http://dx.doi.org/10.1016/S0731-7085(00)00445-3

[13] Food and Drug Administration, HHS (2003) International Conference on Harmonisation; Stability Data Package for Registration Applications in Climatic Zones III and IV; Stability Testing of New Drug Substances and Products; availability. Federal Register Notices, 68, 65717-65718.

[14] Naveed, S., Waheed, N. and Nazeer, S. (2014) Degradation Studies of Ampicillin in API and Formulations. Journal of Applied Pharmaceutical Science, 6, 314-321.

[15] Naveed, S., Naseem, Y., Samie, S., Khan, S. and Ramzan, S. (2014) Degradation Study of Five Different Brands of Ciprofloxacin Using UV-Visible Spectrophotometer and Their Comparative Study. IRJP, 5, 189-190.

[16] Naveed, S., Shafiq, A., Khan, M., Jamal, M., Zafar, H., et al. (2014) Degradation Study of Available Brands of Metformin in Karachi Using UV Spectrophotometer. Journal of Diabetes Metabolism, 5, 328. http://dx.doi.org/10.4172/2155-6156.1000328 